\title{
Modeling of facade leaching in urban catchments
}

\author{
S. Coutu, ${ }^{1}$ D. Del Giudice, ${ }^{1,2,3}$ L. Rossi, ${ }^{1}$ and D. A. Barry ${ }^{1}$ \\ Received 8 May 2012; revised 30 August 2012; accepted 24 October 2012; published 6 December 2012.
}

[1] Building facades are protected from microbial attack by incorporation of biocides within them. Flow over facades leaches these biocides and transports them to the urban environment. A parsimonious water quantity/quality model applicable for engineered urban watersheds was developed to compute biocide release from facades and their transport at the urban basin scale. The model couples two lumped submodels applicable at the basin scale, and a local model of biocide leaching at the facade scale. For the facade leaching, an existing model applicable at the individual wall scale was utilized. The two lumped models describe urban hydrodynamics and leachate transport. The integrated model allows prediction of biocide concentrations in urban rivers. It was applied to a $15 \mathrm{~km}^{2}$ urban hydrosystem in western Switzerland, the Vuachère river basin, to study three facade biocides (terbutryn, carbendazim, diuron). The water quality simulated by the model matched well most of the pollutographs at the outlet of the Vuachère watershed. The model was then used to estimate possible ecotoxicological impacts of facade leachates. To this end, exceedance probabilities and cumulative pollutant loads from the catchment were estimated. Results showed that the considered biocides rarely exceeded the relevant predicted no-effect concentrations for the riverine system. Despite the heterogeneities and complexity of (engineered) urban catchments, the model application demonstrated that a computationally "light" model can be employed to simulate the hydrograph and pollutograph response within them. It thus allows catchment-scale assessment of the potential ecotoxicological impact of biocides on receiving waters.

Citation: Coutu, S., D. Del Giudice, L. Rossi, and D. A. Barry (2012), Modeling of facade leaching in urban catchments, Water Resour. Res., 48, W12503, doi:10.1029/2012WR012359.

\section{Introduction}

[2] Biocides are active, ecotoxic substances used for material protection via reduction of microbially induced deterioration [Burkhardt et al., 2007, 2009]. Urban-derived biocides have received less attention than agricultural pesticides, for example, mainly due to their underestimation in terms of both usage and potential for impairing water quality [Wittmer et al., 2011a]. Recently, biocide discharge rates in waters of a semiurban catchment were found to be up to an order of magnitude higher than agricultural pesticide discharges. Furthermore, they can be bioaccumulative

\footnotetext{
${ }^{1}$ Laboratoire de Technologie Écologique, Institut d'Ingénierie de l'Environnement, Faculté de l'Environnement Naturel, Architectural et Construit (ENAC), École Polytechnique Fédérale de Lausanne (EPFL), Lausanne, Switzerland.

${ }^{2}$ Now at Eawag, Swiss Federal Institute for Aquatic Science and Technology, Ueberlandstrasse, Duebendorf, Switzerland.

${ }^{3}$ Also at Swiss Federal Institute of Technology Zürich (ETHZ), Zürich, Switzerland.

Corresponding author: S. Coutu, Laboratoire de Technologie Écologique, Institut d'Ingénierie de l'Environnement, Faculté de l'Environnemen Naturel, Architectural et Construit (ENAC), Station 2, École Polytechnique Fédérale de Lausanne (EPFL), 1015 Lausanne, Switzerland. (sylvain.coutu@ epfl.ch)

(C)2012. American Geophysical Union. All Rights Reserved. 0043-1397/12/2012WR012359
}

and persistent (i.e., low degradation rates) in the environment, which make them a source of considerable concern [Burkhardt et al., 2011].

[3] A major source of biocides in urban environments is facade leaching of paints under wet-weather conditions [Wittmer and Burkhardt, 2009; Burkhardt et al., 2011]. Compounds applied as biocides have been detected in combined sewer overflows (CSOs), in effluents of urban wastewater treatment plants (WWTPs), and storm water drains [Burkhardt et al., 2007; Wittmer et al., 2010]. Via these pathways, biocides can enter natural water bodies such as lakes and rivers situated downstream of urban areas. Experimental investigations on biocide release from building envelopes have been reported at the facade [e.g., Schoknecht et al., 2009; Burkhardt et al., 2011] and subcatchment scales [e.g., Burkhardt et al., 2007]. Recently, Wittmer et al. [2011b] and Coutu et al. [2012a] reported modeling studies that considered wash-off of biocides from treated facades. However, no mathematical model that predicts the transport and fate of biocides in urban catchments once released from facades has been presented.

[4] Environmental risk assessment of facade biocides requires modeling of their release from facades to their eventual possible arrival in receiving waters. Such a model can be built by coupling of appropriate hydrodynamic and water quality models. The need for integrated models that are capable of simulating pollutographs of diffuse or point-source 
pollution is recognized as an important challenge in urban hydrology [Zoppou, 2001; Freni et al., 2011], and recent literature has pointed to the need for such models [Delleur, 2003; Elliott and Trowsdale, 2007; Jacobson, 2011]. For risk assessment, features necessary in such a model include the ability to capture urban hydrodynamics and associated water quality signals on short time scales [Elliott and Trowsdale, 2007].

[5] Our aim is to present a model for prediction of facade-sourced biocide in receiving waters, which will be capable of forecasting the temporal variability of dissolved biocides at the urban basin scale. An existing lumped-parameter hydrological model that has proven its efficiency to replicate flow dynamics in engineered watersheds is adopted [Coutu et al., 2012b]. This submodel is coupled to biocide generation (facade-level, upscaled to catchment scale) and transport modules of commensurate complexity, in order to create an integrated model able to predict the facade-biocide response of an urban watershed. The model is then field validated and subsequently applied to predict risk of biocides in natural waters.

\section{Modeling Approach}

\subsection{Urban Hydrology}

[6] In order to assess the pollutant response of a hydrosystem, it is first necessary to reproduce correctly its hydrologic response. A lumped model is used to predict discharge dynamics at the outlet of the urban river basin. As noted by Samaniego et al. [2010], such parsimonious models are computationally efficient compared with fully distributed simulators. At the same time, these tools offer the advantage of providing an interpretable representation of the hydrological behavior of the catchment [Fenicia et al., 2006] and have been successfully tested for diffuse sources of pollution in rural environments (e.g., Rinaldo et al. [2006] or Basu et al. [2010]). Here, the drainage basin is modeled as a set of three reservoirs, each one characterized by a state variable representing the water storage in the compartment (Figure 1). The two meteorological forcings to the hydrosystem are precipitation $j$ and air temperature $\mathcal{T}$, both of which are assumed to be uniform over the watershed.

[7] Both overland and subsurface water flow are considered. The surface compartment, responsible for surface runoff, is modeled as a fast-reacting (transient) storage characterized by a water volume of $S_{s}$ [cp., Fenicia et al., 2007]. The subsurface flow is modeled using two reservoirs: The vadose (or root) zone region and the groundwater region with, respectively, storages of $S_{u}$ and $S_{g}$ [Botter et al., 2010]. The root-zone and groundwater reservoirs are considered to be extended over the total surface of the catchment, whereas the surface compartment occupies only the pervious fraction (Figure 1). The groundwater reservoir controls base flow to the river. The total hydrologic response of the watershed $Q_{\text {tot }}$ is computed by combining linearly the (transient) outflow produced by the reservoirs. Details of the hydrological framework are given by Coutu et al. [2012b].

\subsection{Pollutant Generation on Facades and Basin-Scale Transport}

[8] In this section, a water quality model that can be coupled with the lumped catchment flow model shown in

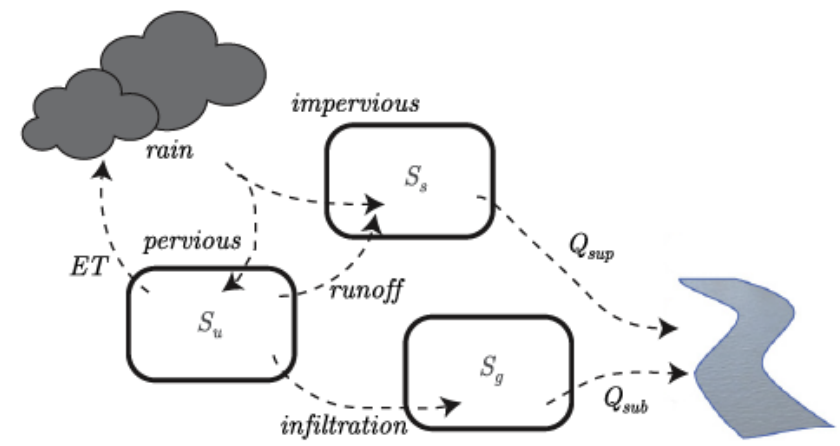

Figure 1. Model of urban watershed flow [Coutu et al., 2012b]. Rainwater $(j)$ lands on pervious $\left(S_{u}\right)$ or impervious $\left(S_{s}\right)$ surfaces in proportion to the exposure of each surface type. When the rainfall flux exceeds that maximum soil infiltration capacity, runoff occurs from the pervious to the impervious area. Water from the impervious area is discharged rapidly $\left(Q_{\text {sup }}\right)$ to the river through the drainage system. Water in the vadose zone $\left(S_{u}\right)$ flows to a subsurface reservoir $\left(S_{g}\right)$ that discharges slowly $\left(Q_{\text {sub }}\right)$ to the river. Model equations defining these fluxes are presented by Coutu et al. [2012b].

Figure 1 is presented. The modeling approach groups biocide processes into (1) generation (input), (2) removal, and (3) transport.

\subsubsection{Biocide Generation}

[9] Biocide is released from paints and renders that protect facades from biologically induced deterioration. Transport of biocide from leached facades is considered here. Recently, Coutu et al. [2012a] presented a single-facade leaching model that takes into account facade length. On a given individual facade, their two-compartment model simulates the leaching process as the transfer of biocide from one compartment (the wall) to another (surface flow on the facade). In the wall matrix, the biocide migrates to the wall surface following a diffusion-limited process, which is represented as an exponential decay. Once on the surface of the facade, the biocide is available for leaching. Leaching to rainwater runoff and exchange between the runoff and the wall surface is modeled with detachment-deposition rates. Leached biocide is advected in the rainwater to the bottom of the facade. Diffusion within the runoff volume is not considered. Figure 2 illustrates the dynamics of biocides at facade scale.

[10] The model takes into account building height, a feature that allows simulation of leaching of a collection of buildings using cadastral data. By this approach, upscaled (basin scale) estimates of facade leaching based on cadastral data are possible. This upscaling relies on the assumption that leaching of a given facade is independent of any other, such that the response of the distribution of facade lengths (and other relevant cadastral data) can be summed linearly over the distribution. In practice, we simplified the distribution to its mean, i.e., the upscaled facade leaching estimates were based on mean amount of biocide per unit area, total facade surface, mean facade height, and mean age of facade coatings. In other words, the basin-scale response is based on the average facade in the urban area 


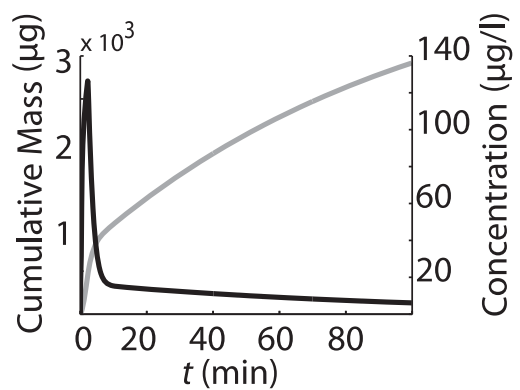

Figure 2. Dynamics of simulated load (gray) and concentration (black) of a typical biocide at the bottom of a $2 \mathrm{~m}$ high facade during a constant rain event. The presented curve can be affected by facade height and paint age. More details on the modeling can be found by Coutu et al. [2012a].

considered, an approach that gives very similar results to those using the distribution of facades [Coutu et al., 2012a]. Then, the facade-leaching model provides the temporal distribution of the biocide as a function of rainfall. The dynamics of biocide mass at the facade bottom are given by $m_{\mathrm{fac}}$, and reflects catchment-averaged weather conditions (rainfall intensity and wind direction).

\subsubsection{Removal Processes}

[11] Contaminated water leaving the average facade can reach surface flow, or enter the soil. To simplify matters as much as possible, we assume that biocide in water entering the soil is sorbed or otherwise removed, whereas biocides in the overland flow do not undergo any alterations. We expand on the basis for this approach in the following.

[12] Biocides leached from facades can undergo a variety of processes, such as sorption, degradation, etc., depending on the circumstances. The separation of the water entering the soil after contact with the facade and that reaching the overland is included in the parameter $k_{\text {isd }}$. Specifically, $k_{\text {isd }} 1$ of the leached biocide reaches the surface water flow, with the rest entering the soil. In urban conditions, buildings are usually surrounded by trenches or gardens designed to enhance infiltration of water flowing from facades, thus the vast majority of the biocide will enter the soil rather than surface runoff, in which case $k_{\text {isd }} \gg 1$. Biocides reaching the soil are considered to be completely immobilized or degraded since (1) the three studied pollutants show a high affinity to soil, as confirmed by relatively high soil water partition coefficients (see Table 1), and (2) once in the soil, biocides can undergo uptake processes, microbial degradation, hydrolysis, or other degradation phenomena [Appelo and Postma, 2005]. Our simplified approach is consistent with recent work of Burkhardt et al. [2011]. They found that during dry conditions baseline biocide concentrations were below detection limits in urban receiving streams, whereas high concentrations were detected in storm water runoff. Biocide that does not enter the soil is transported over impervious surfaces with runoff, where it is considered as completely mixed with storm water. This runoff water can either reach the sewer network (and hence the WWTP) or the river system (for an urban area equipped with a partially separated sewer system), as is calculated in the hydrological submodel. In our model application we consider biocide data for a river, not a WWTP.

[13] The solute mass flux emitted by building facades $\dot{m}_{\text {fac }}$ is thus reduced as follows:

$$
\dot{m}_{\text {in }}(t)=\frac{\dot{m}_{\text {fac }}(t)}{k_{\text {isd }}} p_{\text {hyb }}
$$

where $k_{\text {isd }}$ is the scaling factor accounting for the partitioning of runoff from facades, and $p_{\text {hyb }}$ is the proportion of storm water flow diverted to the river (i.e., $1-p_{\text {hyb }}$ is diverted to the WWTP). In fact, when modeling a river basin including an urban area equipped with a partially separated sewer system (hybrid, hyb), a fraction of storm water, and therefore of biocide, is diverted to the WWTP through the pipe system. The mass flux from facades that enters the overland flow is denoted by $\dot{m}_{\text {in }}$. Note that $k_{\text {isd }} \geq 1$ and $0 \leq p_{\text {hyb }} \leq 1$.

Table 1. Characteristics of the Most Common Biocides Found in Surface Waters [Wittmer and Burkhardt, 2009; Wittmer et al., 2010, 2011a]

\begin{tabular}{|c|c|c|c|c|c|c|}
\hline Biocides & Function & Usages & $\begin{array}{l}\text { Main Driving } \\
\text { Factors }\end{array}$ & Half-Life (days) & $K_{d}\left(1 \mathrm{~kg}^{1}\right)$ & $\begin{array}{l}\mathrm{PNEC}^{\mathrm{a}} \\
\left(\mathrm{ng} \mathrm{L}^{1}\right)\end{array}$ \\
\hline Diuron & Herbicide, algicide & $\begin{array}{l}\text { Facades, preservatives, } \\
\text { pesticide (fruit, asparagus), etc. }\end{array}$ & Urban rain driven & $\begin{array}{l}\text { Soils: } 90,{ }^{\mathrm{b}} \\
\quad \text { water: }>43^{\mathrm{c}, \mathrm{d}}\end{array}$ & $3.114 .7^{\mathrm{e}}$ & 20 \\
\hline Terbutryn & Herbicide, algicide & Bathrooms, facades, etc. & $\begin{array}{l}\text { Urban rain driven, } \\
\text { urban continuous }\end{array}$ & $\begin{array}{l}\text { Soils: } 1428,{ }^{\mathrm{f} g} \\
\text { water: } 180240^{\mathrm{h}}\end{array}$ & $1.518 .2^{\mathrm{h}, \mathrm{i}}$ & 34 \\
\hline Carbendazim & Fungicide & $\begin{array}{l}\text { Bathrooms, facades, pesticide } \\
\text { (fruit, vegetables), etc. }\end{array}$ & $\begin{array}{l}\text { Urban rain driven, } \\
\text { household }\end{array}$ & $\begin{array}{l}\text { Soils: } 832,{ }^{\mathrm{j}} \\
\text { water: } \text { stable }^{\mathrm{k}}\end{array}$ & $8.135^{\mathrm{k}}$ & 34 \\
\hline
\end{tabular}

\footnotetext{
${ }^{\mathrm{a}}[$ Burkhardt et al., 2009]

$\mathrm{b}$ [Prichard et al., 2005]

chttp://www.cdpr.ca.gov/docs/emon/pubs/fatememo/diuron.pdf, site last accessed on 02/04/2012.

${ }^{d}$ http://www.epa.gov/espp/litstatus/effects/diuron efed chapter.pdf, site last accessed on 02/04/2012.

e [Dores et al., 2009]

f $[$ Avidov et al., 1985]

${ }_{\mathrm{g}}^{\mathrm{http}}$ ://extoxnet.orst.edu/pips/terbutry.htm, site last accessed on 02/04/2012.

h [Wu et al., 1974]

i[Barriuso et al., 1992]

${ }^{\mathrm{j}}$ http://www.sea.eawag.ch/inhalt/sites/stoffe/pdf/Biozide e.pdf, site last accessed on 02/04/2012.

${ }^{\mathrm{k}}$ [Berglof et al., 2002]
} 


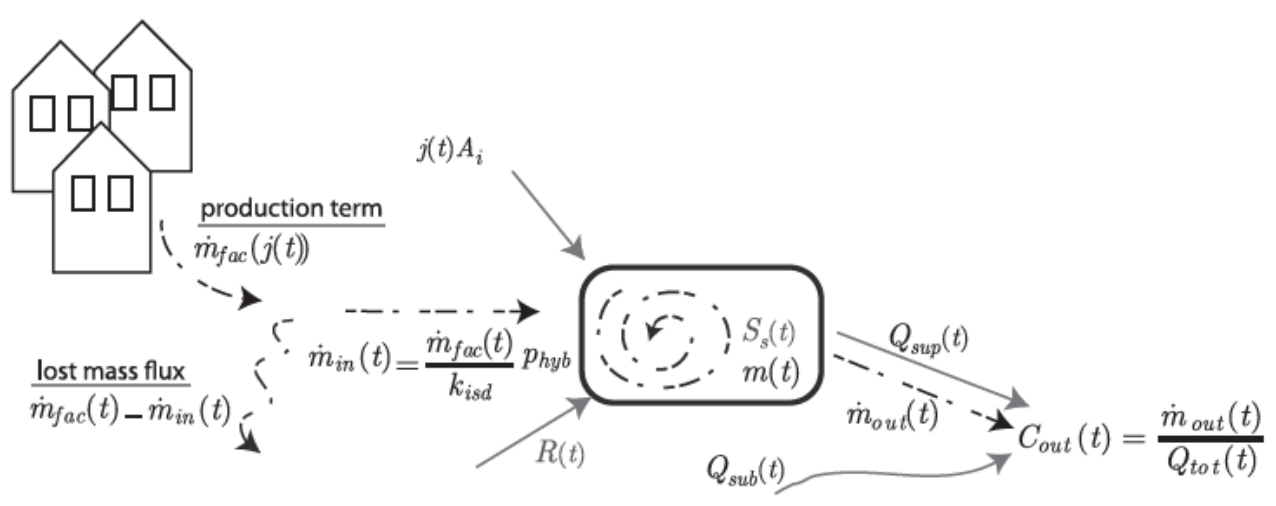

Figure 3. Schematic representation of the basin-scale biocide transport model. Biocides leach from facades at a rate $\dot{m}_{\text {fac }}$, based on upscaling the model of Coutu et al. [2012a]. Some biocide is diverted out of the river catchment through the combined sewer system (a fraction $1-p_{\text {hyb }}$ ) and some is lost due infiltration/sorption/ degradation (a fraction $\left(1-k_{\text {isd }}\right) / k_{\text {isd }}$, see equation (1)). The remaining fraction $\left(\dot{m}_{\text {out }}\right)$ mixes in the surface reservoir with rainwater $\left(j A_{i}\right)$ and is flushed to the river $\left(\dot{m}_{\text {out }}\right)$, where it is mixed in the total flow $\left(Q_{\text {tot }}\right)$. Solid arrows show water transport and dashed arrows illustrate biocide pathways.

\subsubsection{Biocide Transport}

[14] The residual mass flow rate available for transport $\dot{m}_{\text {in }}$ enters the surface hydrologic reservoir, which is considered to be a completely mixed linear reactor with two dynamic variables, biocide mass $m$ and water volume $S_{s}$. The rate of change of pollutant mass in this one-compartment model is given by

$$
\dot{m}=\dot{m}_{\text {in }} \quad \dot{m}_{\text {out }}=\dot{m}_{\text {in }} \quad \frac{Q_{\text {sup }}}{S_{s}} m .
$$

The biocide flux out of the surface reservoir is given by $\dot{m}_{\text {out }}$ in equation (2). This equation and all other differential equations of the model were solved using a first-order Euler scheme. Although this scheme is often considered as poorly stable [Beers, 2006], it was found to be efficient in this context. Furthermore, other numerical methods (not presented here) were tested with no changes observed in the results.

[15] The biocide concentration of at the outlet of the watershed $C_{\text {out }}$ is given by

$$
C_{\text {out }}(t)=\frac{\dot{m}_{\text {out }}(t)}{Q_{\text {tot }}(t)},
$$

where $Q_{\text {tot }}=Q_{\text {sup }}+Q_{\text {sub }}$ is the total hydrological response of the catchment.

[16] The procedure leading to the construction of the integrated water quantity and quality model is summarized in Figure 3 . The biocide mass flux from the upscaled facadeleaching submodel is transferred to the transport submodel. This biocide flux from the basin's facades is reduced by a certain factor $\left(p_{\text {hyb }} / k_{\text {isd }}\right)$ to account for different removal phenomena, as described previously. In summary, the contaminant compartment receives the residual biocide flux, which is mixed with surface water to create a bivariable compartment model. The biocide discharged is further diluted by the streamflow.

\subsubsection{Calibration Procedure}

[17] A two-component metric was adopted to calibrate the water quality model. Note that $k_{\text {isd }}$ is the only calibrated parameter of the biocide transport model. The quality of the prediction was estimated using the Nash-Sutcliffe (NS, optimal value of one) and the normal-bias (NB, optimal value of 0 ) coefficients. The optimization used [Hingray et al., 2009]

$$
\operatorname{Min}\left\{\left(\begin{array}{ll}
1 & \mathrm{NS}
\end{array}\right)+|\mathrm{NB}|\right\} .
$$

[18] This multicriteria calibration procedure is recommended for better comprehension of the model performance [Hingray et al., 2009]. Note that the hydrological model was calibrated separately in another study [Coutu et al., 2012b]. Separation of the hydrological and water quality calibrations is warranted in order to obtain satisfactory concentration simulations without impacting on the water discharge predictions [Kirchner, 2006].

\section{Case Study}

\subsection{Site Description}

[19] The model was applied to a meso- $\gamma$ scale system [Orlanski, 1975], the Vuachère river basin, located in the eastern part of the city of Lausanne, Switzerland (Figure 4). The total area of the catchment is $15 \mathrm{~km}^{2}$, of which approximately $34 \%$ is covered by impervious surfaces. According to data reported by Jordan [2010], about $60 \%$ of runoff generated on these surfaces contributes to the river discharge, while the rest flows into the sewer system. This value of 0.6 , the "separation proportion," corresponds to the loss factor $p_{\text {hyb. }}$.

[20] Through a GIS analysis (http://www.swisstopo.admin. $\mathrm{ch} /$, site last accessed on 28 August 2012) of cadastral data, the total surface area and mean height of the catchment's buildings were estimated as, respectively, $8.8 \times 10^{6} \mathrm{~m}^{2}$ and $17 \mathrm{~m}$. According to Coutu et al. [2012a], windows and doors lead to a reduction of about one third of the facade area. Data for Switzerland on facade biocide treatment in 2007 [Wittmer et al., 2011a] were taken as representative for the Vuachère 


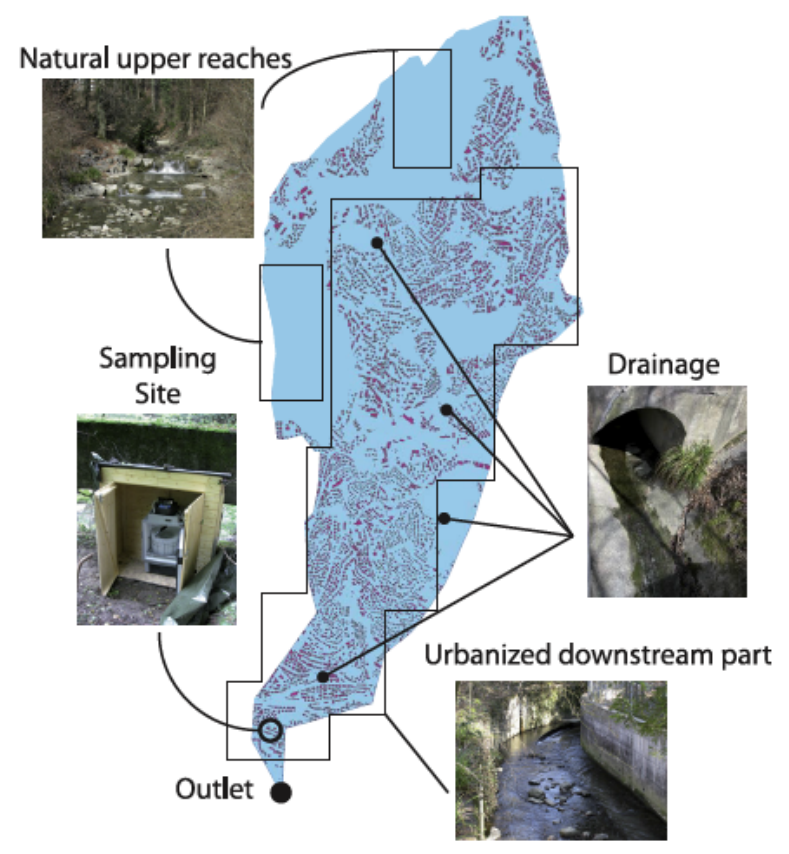

Figure 4. Overview of the Vuachère river basin. Buildings are represented by pink polygons, while the colored area is the drainage basin. The drainage system takes rainfall-runoff (and biocides) to the river. The sampling site is located close to river outlet.

river basin: $60 \%$ of facades have biocide treatment. We examined three major biocides, which were considered to have been applied according to their market share: carbendazim $40 \%$, diuron $30 \%$, and terbutryn $30 \%$.

[21] To estimate the actual masonry surface which undergoes leaching during rain, the prevalent wind direction must be considered. Indeed, wind velocity along with building characteristics influence the amount of rain coming into contact with facades and thus affect the amount of biocides leached. Facades exposed to the prevalent wind direction undergo greater leaching than protected facades. On average about $75 \%$ of the basin's facades [Blocken and Carmeliet, 2004; Abuku et al., 2009; Coutu et al., 2012a] are protected in any given rain event.

[22] Taking these factors into account, the facade surface area exposed to leaching in the Vuachère basin was estimated as $8.8 \times 10^{5} \mathrm{~m}^{2}$.

\subsection{Experimental Data at the Vuachère River Outlet}

[23] Water quantity and quality data were collected at the outlet of the Vuachère basin. Discharge dynamics were calculated using continuously recorded water stages (http://echo.epfl.ch/, site last accessed on 28 August 2012).

[24] Biocide concentration measurements were obtained through a sampling campaign. As described by Ort et al. [2010], concentration dynamics should be determined on the basis of appropriate sampling intervals, in order to increase the likelihood of capturing concentration pulses. Although sampling intervals depend on the characteristics of the catchment and chemicals under investigation, high frequency sampling is recommended $\left(>1\right.$ sample $^{{ }^{1}}{ }^{1}$ ).

[25] Transport of facade biocides is controlled by rain events [e.g., Wittmer et al., 2011a]. Thus, concentration spikes will occur with storm hydrographs. Based on these considerations, an automatic sampler was programmed to draw a series of aliquots after a certain water level was exceeded in the Vuachère river. In total, biocide concentrations were measured for four storm events of modest intensity in spring 2011. Storm events where respectively $6 \mathrm{~h}$, $1 \mathrm{~h}, 40 \mathrm{~min}$ and $4 \mathrm{~h}$ long, with a total rainfall of $8.5,2.5$, 3.5 , and $7 \mathrm{~mm}$, respectively.

\section{Results and Discussion}

\subsection{Hydrographs and Pollutographs}

[26] Figure 5 shows the comparison between measured and simulated discharges during the sampling period. This hydrograph was discussed by Coutu et al. [2012b], where the hydrological model (section 2.1) was presented and validated. We do not repeat that discussion here, but simply show the hydrograph as it is essential to prediction of the pollutograph.

[27] Since the hydrological simulator reproduces satisfactorily the observed discharge time series, the biocide portion of the model is examined. For each substance, the reduction factor $k_{\text {isd }}$ was calibrated. The results of the model adjustment, in terms of water quality predictions, are presented in Figures 6 and 7 .

[28] We see in Figure 6 that the response time of the pollutograph is a few hours, whereas half-lives of the considered substances are in the range of several days (Table 1), which is consistent with our assumption that no degradation occurs during the runoff process. The data indicate that the biocide concentration increases rapidly after the rain starts, behavior that is reproduced by the model. However, due to the fact that the programming of the sampling device was recorded to take samples after a certain water level was exceeded, the decay of biocide concentrations was only partially recorded.

[29] Figure 8 shows that biocide concentrations follow roughly linearly the impulsive rise of the river flow at the beginning of the rain event. The response is fast for flow and biocides, as additional water responsible for flow rise is generated principally by impervious surfaces in the steep, urbanized Lausanne basin. This initial episodic concentration behavior comes from the dynamics of the source model (see Figure 2 and Coutu et al. [2012a]). During dry weather, biocides accumulate on facade surfaces at rainfall start and are readily removed by rainfall. When the flow rate starts to decrease, concentrations remain high so long as the surface runoff contribution dominates inflow to the river. As indicated above, in our model surface runoff controls biocide concentrations because biocides in water that infiltrates the soil are sorbed or degraded. Subsurface flow contributes to the stream hydrograph on longer time scales than the flashy surface runoff. In consequence, biocide concentrations decrease during the hydrograph recession, as contribution of nonpolluted infiltrated water increases.

[30] The measured and computed pollutographs at the outlet of the hydrosystem exhibit close agreement. The model allows prediction of biocide dynamics at a high temporal resolution, which is controlled by the flow model input data. Previous studies have shown the complexity of matching data from a high resolution sampling campaign and model results [Massoudieh et al., 2008]. Also, because of the complexity of organizing automatic high-frequency sampling campaigns, solute transport models are often 


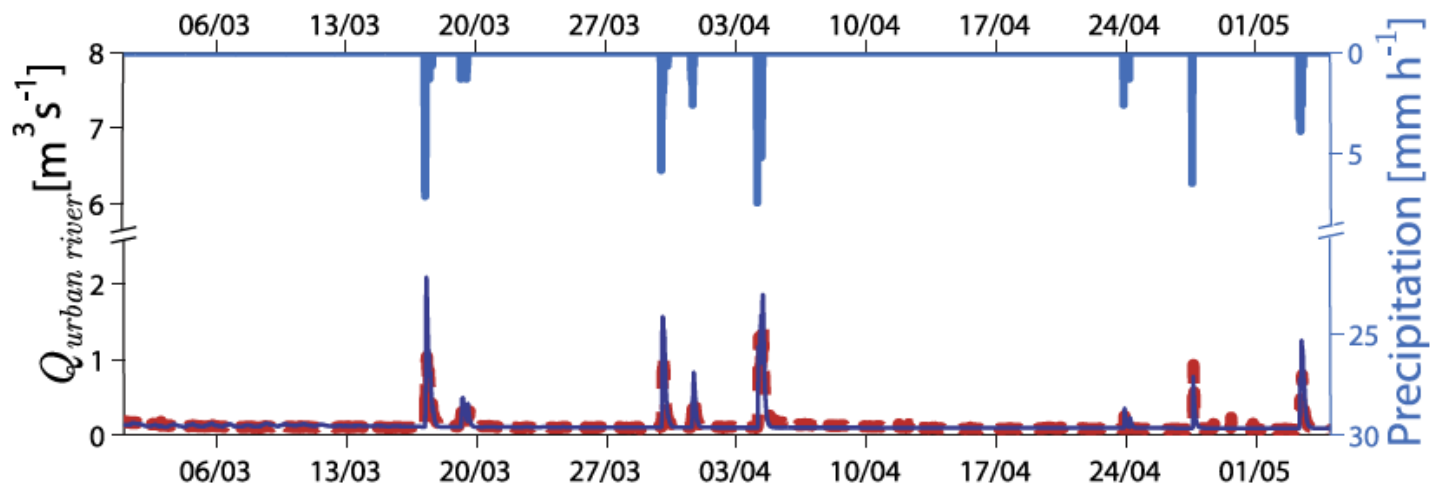

Figure 5. Predicted (line) and measured (dots) flow rate at the outlet of Vuachère river basin. Precipitation is shown in blue on the right vertical axis [Coutu et al., 2012b].

calibrated using averaged concentrations, with averages taken over an hour or more [e.g., Matsui et al., 2006; Riml and Wörman, 2011], rather than the high frequency dynamics of biocide transport that are captured here.

[31] In our model, the scaling parameter $k_{\text {isd }}$ describes the partitioning of facade-emitted biocide at the catchment scale. However, for such a simplified approach we do not expect that $k_{\text {isd }}$ correlates with the sorption coefficient $K_{d}$, as $k_{\text {isd }}$ represents partitioning of water from facades as well as all biogeochemical degradation processes as well as spatial variability that the biocide undergoes during its transfer from the facade to the river outlet. In addition, there is considerable uncertainty in the mass of the three different substances on facades, which in our case was based on a Swiss study (see section 3.1). It is likely that the distribution of these substances on the considered basin varies, albeit in a manner that has not been determined, which could also underpin the lack of correlation observed between $K_{d}$ and $k_{\text {isd }}$.

[32] The calibrated hydrologic-transport model was employed to study cumulative biocide loads released from
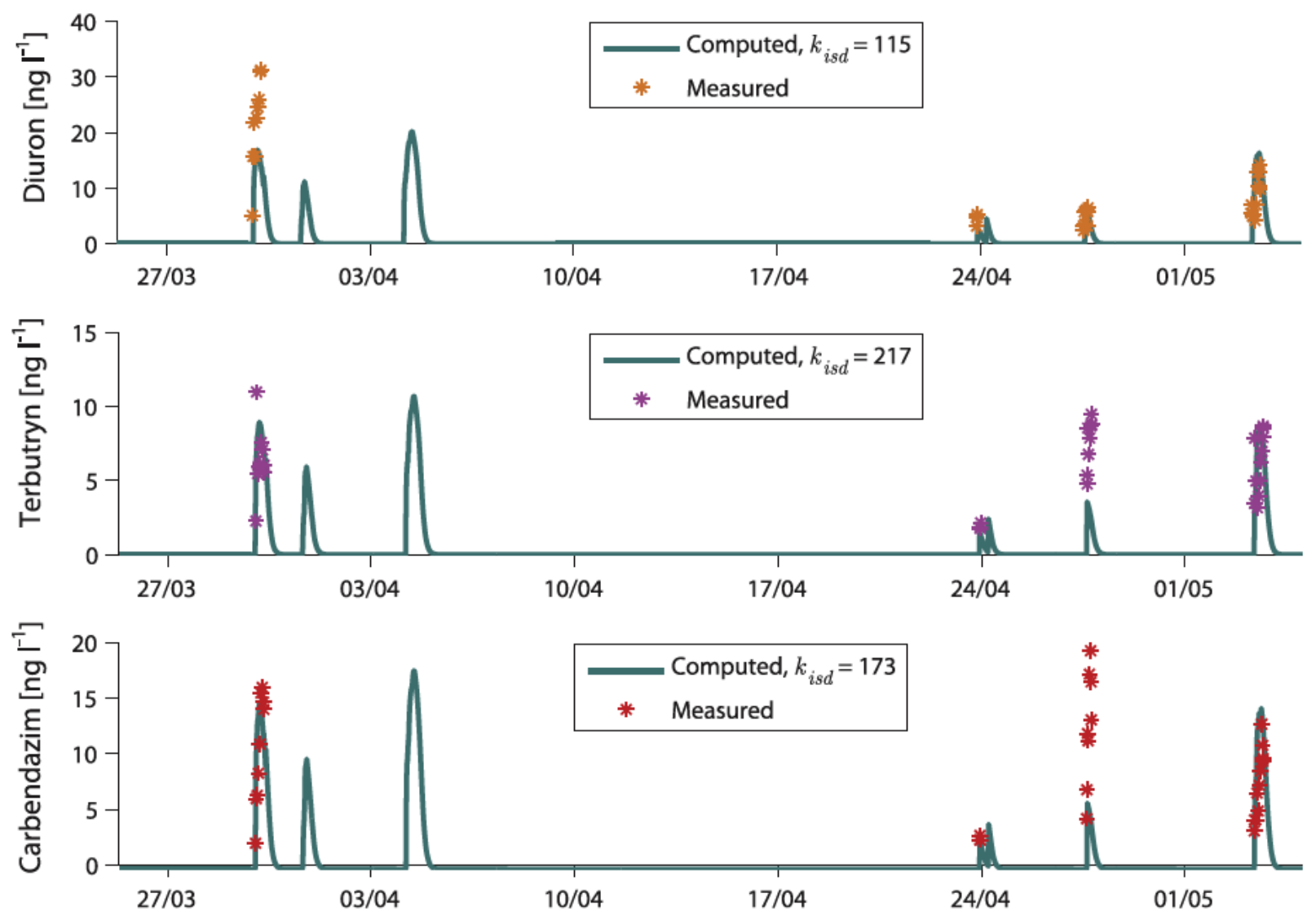

Figure 6. Comparison between observed and simulated pollutographs for the Vuachère hydrosystem. Three substances were investigated: diuron, terbutryn, carbendazim. Two rainfall events were not sampled (03/31 and 04/04). 


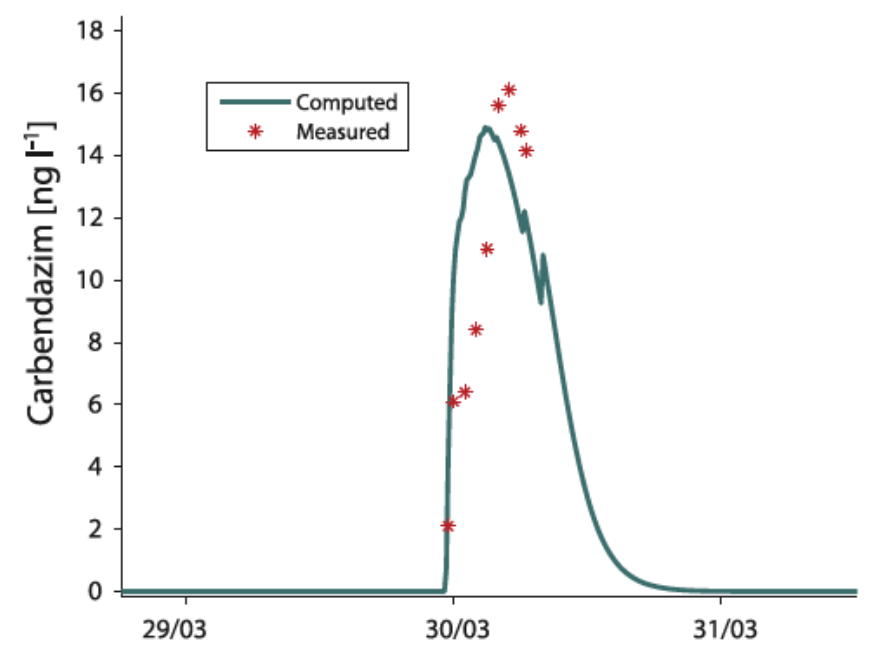

Figure 7. Enlarged view of the first concentration peak (observed and modeled, 29/03 on Figure 6) for carbendazim.

facades and reaching Lake Geneva via the Vuachère River over 1 year (May 2010-April 2011). Results are plotted in Figure 9 for cumulative loads computed at the facade bottom and the river outlet. Storms occurring after dry periods produce more intense biocide release than those taking place after wet weather since, as already noted, biocides accumulate on facade surfaces during these periods [Burkhardt et al., 2011; Coutu et al., 2012a].

[33] Only a small portion of biocides emitted by facades exit the basin. Figure 9 shows that around $0.35 \%$ of the leached biocide mass reaches the outlet, which translates into an annual load to Lake Geneva of approximately $25 \mathrm{~g}$ of each biocide. This figure must be considered with caution due to the uncertainty of the integrated modeling approach, principally in the amount of biocide available on facade surface [Burkhardt et al., 2012; Coutu et al., 2012a]. In addition, the proposed methodology did not consider transport of biocides via particulate matter. Even so, based on our results it is possible to estimate roughly the amount of biocides reaching receiving waters in Switzerland, assuming that the Vuachère basin can be considered as representative. Large amounts of biocides are used annually in urban areas of Switzerland [Wittmer and Burkhardt, 2009]. Coutu et al. [2012a] estimated that approximately $30 \%$ of applied facade coatings are leached annually, and so are available for transfer from facade bottoms to receiving waters. Wittmer and Burkhardt [2009] and Burkhardt et al. [2011] estimated that, conservatively speaking, about $100 \mathrm{t}$ of biocides are used annually for facade protection in Switzerland. From these values we estimate that in Switzerland about $100 \mathrm{~kg}$ of biocides are transferred to receiving waters each year, and that hundreds of kilograms infiltrate into soils. This estimate might be a lower bound, as it does not consider biocides that are routed to WWTPs.

\subsection{Risk Analysis}

[34] To analyze the environmental risk of computed biocide loads, a statistical analysis of stream concentrations was performed. In Figure 10, the predicted no-effect concentrations (PNECs) of the considered biocides [Burkhardt et al., 2009] are plotted together with the concentration duration curves, representing the probability that the biocide's concentration at the catchment exit is exceeded during the year. The figure

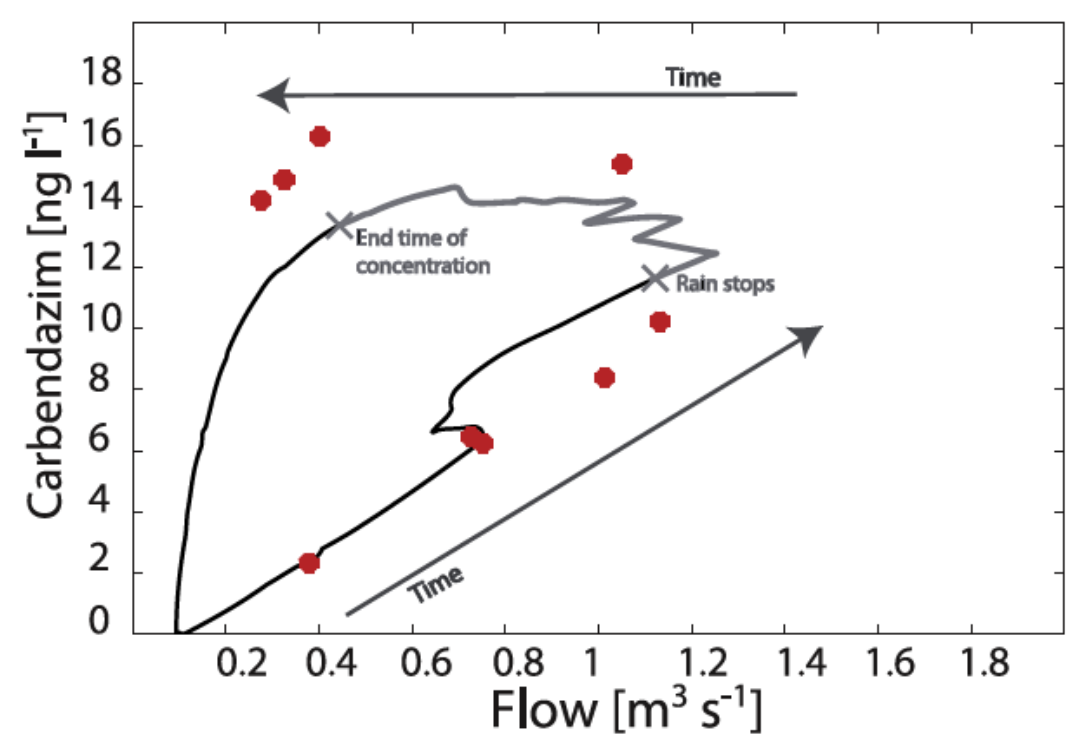

Figure 8. Carbendazim concentration against flow for the first peak in concentration observed (see Figure 6,29/03). Data are shown as points and predictions as the solid line. The concentration increases roughly linearly with flow during the flow buildup phase. When the flow rate decreases, the concentration varies little for a certain period before decaying exponentially to zero. As mentioned in the text, concentration measurements were not collected during the decay period. The cessation of rainfall is indicated with a cross. The time of concentration of the studied basin $(\sim 2 \mathrm{~h})$ is illustrated with the gray line. After this time period, the contribution of infiltrated water $\left(Q_{\text {sub }}\right)$ starts to dominate the global hydrograph instead of surface runoff $\left(Q_{\text {sup }}\right)$. According to our modeling approach, the infiltrated water is free of biocide. 

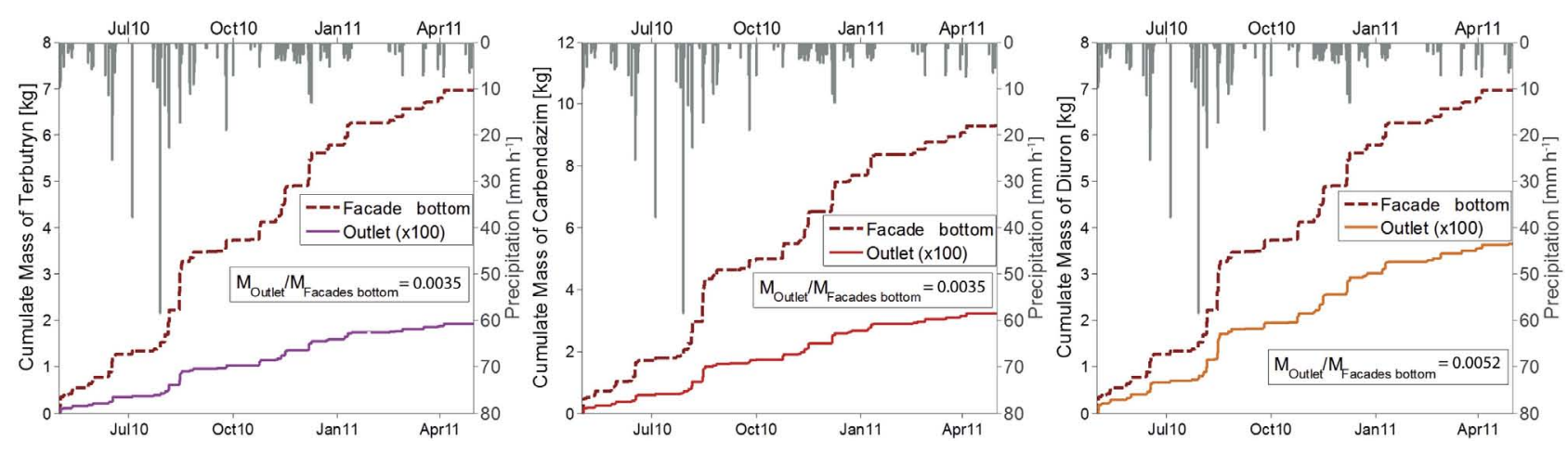

Figure 9. Cumulative input and output biocide masses for the Vuachère hydrosystem, released by precipitation events. The accumulated load at the outlet of the watershed is multiplied by 100 for the sake of visualization. The ratio of the two annual loads is also shown.

illustrates that the calibrated model computes concentrations that are mostly lower than the environmental PNEC. Diuron is the only exception, although it has only a low probability of exceeding its critical value. Again, results of the risk analysis should be taken with caution due to the abovementioned uncertainties.

[35] The calibrated model occasionally underpredicted measured concentrations, sometimes by a factor of 2 . In consequence, a safety factor of 2 may be applied to the modeling results when performing risk assessment. It terms of risk frequency, this would correspond to using half the PNEC values presented in Figure 10. To apply this safety factor of 2 would lead to new exceedance probabilities: $9 \%$ for diuron and $5 \%$ for carbendazim to exceed PNEC/2. The exceedance probability for terbutryn remains zero. Note that exceedance probabilities were computed by including dry weather and wet weather periods. If rainy periods are considered only, probability for a substance to exceed PNEC is obviously increased substantially since it is during these periods that most biocide is transported.

\subsection{Limitations}

[36] As discussed above, during rain, the dynamics of concentration peaks are reproduced satisfactorily by the integrated model. During some storm events, however, the model predictions and the measured data show differences, up to a factor of about 2, as already stated. This is possibly because we assumed that facades are the only source of biocides to streams, although biocides can be applied for other uses (e.g., agricultural) [Wittmer and Burkhardt, 2009]. The absence of secondary sources could be responsible for the underestimation of the pollutograph of each solute at the catchment outlet. Also, our model treats rainfall as uniform over the catchment, whereas of course it varies spatially, which would interact with the spatial distribution of applied biocides in the catchment. A localized study would be necessary to investigate this issue. On the other hand, our model has the virtue of properly matching the pollutograph not only for one event and substance but for most of the events of all chemicals. Given the high uncertainty inherent to urban environment, especially for substances at the nanogram level, we consider the modeling performance achieved as satisfactory.

[37] It is interesting to observe that the facade model implicitly supposes that the temporal response of all biocides to rainfall events is the same. The model then propagates this behavior through the entire system. In other words, the coupled model assumes that all biocides have the same dynamics but different initial quantities and reduction factors. This behavior is a significant prediction that can be tested in studies of different catchments, with different transport characteristics.

\section{Conclusions}

[38] Biocides leach from building facades and are transported to receiving waters. To analyze their transport at the urban basin scale, a "top-down" hydrologic approach has been adopted [e.g., Sivapalan, 2006; Savenije, 2009; Basu et al., 2010], leading to the creation of a parsimonious, multiprocess biocide transport model. The model includes upscaling and coupling of a facade-scale leaching model with basin-scale hydrologic and biocide transport submodels. The majority of biocides leached from facades are removed before reaching receiving waters. The model includes simple scaling factors that lump these removal processes into a single, basin-scale value.

[39] The modeling framework proposed was applied to simulate the response (viz., hydrographs and pollutographs) of a steep, partly urbanized Swiss river basin. The integrated model was tested using monitoring data collected at the outlet of the catchment. The hydrodynamics of the Vuachère river basin were reproduced with reasonable accuracy by the quasi-linear simulator developed. The simulator also showed a good facility in matching measured pollutographs, with concentrations predicted to within a factor of about 2, although generally the model provided underpredictions. Since the model traces biocides from building facades in the catchment, this agreement between model predictions and data (both in timing and in magnitude) suggests that facades are, indeed, main source of the considered biocides found in the Vuachère.

[40] Encouraged by the satisfactory model validation, we proceeded to estimate the annual biocide load from the Vuachère basin facades to Lake Geneva. The analysis revealed that concentrations were most of the time below PNEC values, and that the total biocide load to the lake was of the order of a few tens of grams per year. One proviso to this estimate is that our field sampling and modeling 

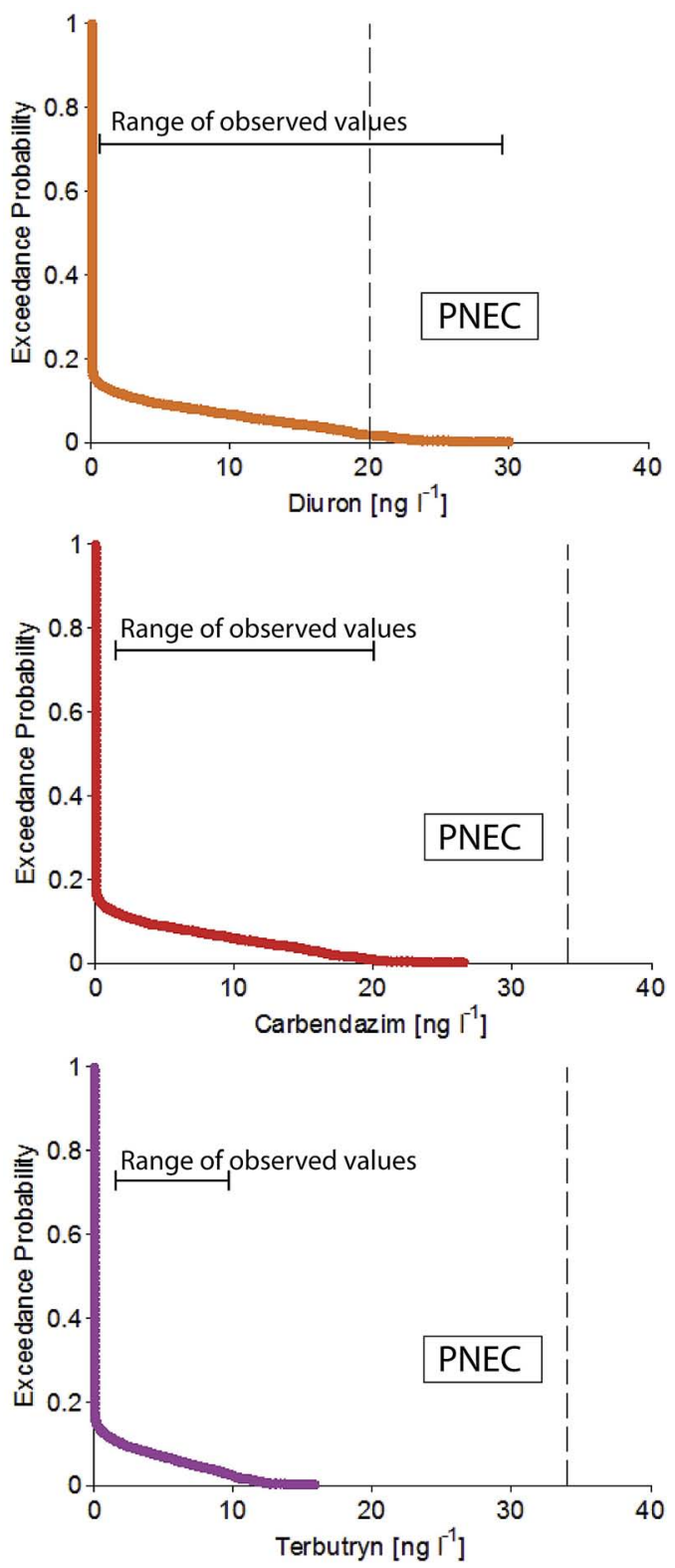

Figure 10. Complementary cumulative distribution function of computed concentrations over 1 year at the outlet of the Vuachère watershed. Critical values for each pollutant are also shown (dashes). The PNEC is exceeded (4\% probability) only for Diuron.

did not account for biocides transported with particles in overland flow.

[41] The model makes use of highly simplified descriptions of the transport process from facade to basin outlet. It is, perhaps, surprising that it performs with the demonstrated accuracy. Its success corroborates the applicability of the well-mixed modeling approximation to basin-scale transport phenomena, where the size of the injection areas (viz. urban surfaces) is much larger than that of heterogeneous features [Rinaldo et al., 2006]. In this vein, it shows that structural heterogeneity of soil and land uses, characterizing semiurbanized zones, does not prevent a conceptually simple, parsimonious hydrological modeling approach from being applied in a realistic setting. However, for each biocide considered, the predicted pollutograph relies on fitting of a single parameter $k_{\text {isd. }}$. That is, calibration of this model parameter is mandatory before predictions can be made.

[42] The flexibility of this methodology permits the future inclusion of other nonpoint sources of aquatic contamination. Furthermore, because the model is computationally undemanding, it allows the possibility of simulating pollutographs for large numbers of urban systems for the purpose of environmental risk assessment and design of protection strategies for downstream ecosystems. On the other hand, the model predictions are based on a large reduction in mass from facades, due to the retention of biocides by soil. This reduction was obtained by calibration, and could not be correlated in any obvious way with the biocide sorption characteristics. Further investigation on whether the reduction factor $k_{\text {isd }}$ could be predicted independently is thus warranted.

\section{Notation}

$A_{i} \quad$ impervious area of the catchment, $L^{2}$.

$A_{p}$ pervious area of the catchment, $L^{2}$.

ET evapotranspiration, $L T^{1}$.

$j \quad$ precipitation rate, $L T^{1}$.

$m_{\text {fac }} \quad$ mass of pollutant at facade bottom, $M$.

$Q_{\text {sub }}$ discharge streamflow of $S_{g}, L^{3} T^{1}$.

$Q_{\text {sup }}$ discharge streamflow of $S_{s}, L^{3} T^{1}$.

$S_{g} \quad$ subsurface reservoir, $L^{2}$.

$S_{s} \quad$ impervious/fast-reacting reservoir, $L^{2}$.

$S_{u} \quad$ Vadose zone reservoir, $L^{2}$.

$\mathcal{T}$ temperature, $\Theta$.

[43] Acknowledgments. The authors thank Htet Kyi Wynn, who was responsible for laboratory analysis of the water samples, Emilie Grand, who participated in field measurements and installation of sampling devices, and Bernard Sperandio, who provided the river flow data. The City of Lausanne is also acknowledged for providing information on the Vuachère river catchment. We would also like to thank the reviewers for the care they took in reviewing this manuscript. Their contribution significantly helped in making the manuscript more comprehensive.

\section{References}

Abuku, M., H. Janssen, J. Poesen, and S. Roels (2009), Impact, absorption and evaporation of raindrops on building facades, Building Environ., 44(1), 113 124, doi:10.1016/j.buildenv.2008.02.001.

Appelo, C., and D. Postma (2005), Geochemistry, Groundwater and Pollution, Taylor \& Francis, Leiden, The Netherlands.

Avidov, E., N. Aharonson, J. Katan, B. Rubin, and O. Yarden (1985), Persistence of terbutryn and atrazine in soil as affected by soil disinfestation and fungicides, Weed Sci., 33, 457461.

Barriuso, E., C. Feller, R. Calvet, and C. Cerri (1992), Sorption of atrazine, terbutryn and 2,4-D herbicides in two Brazilian Oxisols, Geoderma, 53(1 2), 155 167, doi:10.1016/0016-7061(92)90028-6.

Basu, N., P. S. C. Rao, H. E. Winzeler, S. Kumar, P. Owens, and V. Merwade (2010), Parsimonious modeling of hydrologic responses in engineered watersheds: Structural heterogeneity versus functional homogeneity, Water Resour. Res., 46, W04501, doi:10.1029/2009WR007803.

Beers, K. (2006), Numerical Methods for Chemical Engineering: Applications in Matlab, Cambridge University Press, Cambridge, UK.

Berglof, T., T. V. Dung, H. Kylin, and I. Nilsson (2002), Carbendazim sorptiondesorption in Vietnamese soils, Chemosphere, 48(3), 267 273, doi:10.1016/ S0045-6535(02)00096-6.

Blocken, B., and J. Carmeliet (2004), A review of wind-driven rain research in building science, J. Wind Eng. Ind. Aerodyn., 92(13), 10791130 , doi:10.1016/j.jweia.2004.06.003. 
Botter, G., E. Bertuzzo, and A. Rinaldo (2010), Transport in the hydrologic response: Travel time distributions, soil moisture dynamics, and the old water paradox, Water Resour. Res., 46, W03514, doi:10.1029/2009WR 008371 .

Burkhardt, M., T. Kupper, S. Hean, R. Haag, P. Schmid, M. Kohler, and M. Boller (2007), Biocides used in building materials and their leaching behavior to sewer systems, Water Sci. Technol., 56(12), 6367 , doi: 10.2166/wst.2007.807.

Burkhardt, M., M. Junghans, S. Zuleeg, M. Boller, U. Schoknecht, X. Lamani, K. Bester, R. Vonbank, and H. Simmler (2009), Biozide in gebaudefassaden-okotoxikologische effekte, auswaschung und belastungsabschatzung fur gewasser, Umweltwissenschaften Schadstoff-Forschung, 21, 3647.

Burkhardt, M., S. Zuleeg, R. Vonbank, P. Schmid, S. Hean, X. Lamani, K. Bester, and M. Boller (2011), Leaching of additives from construction materials to urban storm water runoff, Water Sci. Technol., 63(9), 1974 1982, doi: 10.2166/wst.2011.128.

Burkhardt, M., S. Zuleeg, R. Vonbank, K. Bester, J. Carmeliet, M. Boller, and T. Wangler (2012), Leaching of biocides from facades under natural weather conditions, Environ. Sci. Technol., 46(10), 5497 5503, doi:10.1021/ es2040009.

Coutu, S., L. Rossi, C. Rota, and D. A. Barry (2012a), Modelling city-scale facade leaching of biocide by rainfall, Water Res., 46, 35253534 , doi:10.1016/j.watres.2012.03.064.

Coutu, S., D. Del Giudice, L. Rossi, and D. A. Barry (2012b), Parsimonious hydrological modeling of urban sewer and river catchments, J. Hydrol., 464, 477 484, doi:10.1016/j.jhydrol.2012.07.039.

Delleur, J. (2003), The evolution of urban hydrology: Past, present, and future, J. Hydraul. Eng., 129, 563 573, doi:10.1061/(ASCE).

Dores, E., C. Spadotto, O. Weber, L. Carbo, A. Vecchiato, and A. Pinto (2009), Environmental behaviour of metolachlor and diuron in a tropical soil in the central region of Brazil, Water Air Soil Pollut., 197(1), 175 183, doi:10.1007/s11270-008-9801-1.

Elliott, A., and S. Trowsdale (2007), A review of models for low impact urban stormwater drainage, Environ. Model. Software, 22(3), 394 405, doi:10.1016/j.envsoft.2005.12.005.

Fenicia, F., D. Solomatine, H. Savenije, and L. Hoffmann (2006), An approach to multi-criteria calibration of hydrologic models and their mixtures, Geophys. Res. Abstr., 8, 06834, doi:1607-7962/gra/EGU06-A06834

Fenicia, F., H. H. G. Savenije, P. Matgen, and L. Pfister (2007), A comparison of alternative multiobjective calibration strategies for hydrological modeling, Water Resour. Res., 43, W03434, doi:10.1029/2006WR 005098 .

Freni, G., G. Mannina, and G. Viviani (2011), Assessment of the integrated urban water quality model complexity through identifiability analysis, Water Res., 45(1), 37 50, doi:10.1016/j.watres.2010.08.004.

Hingray, B., C. Picouet, and A. Musy (2009), Hydrologie 2: Une science pour l'ingénieur, Science et ingénierie de l'environnement, Presses Polytechniques et Universitaires Romandes, Lausanne, Switzerland.

Jacobson, C. R. (2011), Identification and quantification of the hydrological impacts of imperviousness in urban catchments: A review, J. Environ. Manage., 92(6), 1438 1448, doi:10.1016/j.jenvman.2011.01.018.

Jordan, F. (2010), Modélisation du réseau d'assainissement: Outil de diagnostic et de planification en ville de Lausanne, GWA Gas Wasser Abwasser, 90(3), 199208.
Kirchner, J. (2006), Getting the right answers for the right reasons: Linking measurements, analyses, and models to advance the science of hydrology, Water Resour. Res., 42, W03S04, doi:10.1029/2005WR004362.

Massoudieh, A., A. Abrishamchi, and M. Kayhanian (2008), Mathematical modeling of first flush in highway storm runoff using genetic algorithm, Sci. Total Environ., 398(1 3), 107 121, doi:10.1016/j.scitotenv.2008. 02.050 .

Matsui, Y., K. Narita, T. Inoue, and T. Matsushita (2006), Screening level analysis for monitoring pesticide in river water using a hydrological diffuse pollution model with limited input data, Water Sci. Technol., 53(10), 173181

Orlanski, I. (1975), A rational subdivision of scales for atmospheric processes, Bull. Am. Meteorol. Soc., 56(5), 527534

Ort, C., M. G. Lawrence, J. Rieckermann, and A. Joss (2010), Sampling for pharmaceuticals and personal care products (PPCPs) and illicit drugs in wastewater systems: Are your conclusions valid? A critical review, Environ. Sci. Technol., 44(16), 6024 6035, doi:10.1021/es100779n.

Prichard, T., J. Troiano, J. Marade, F. Guo, and M. Canevari (2005), Movement of diuron and hexazinone in clay soil and infiltrated pond water, J. Environ. Qual., 34, 2005 2017, doi:10.2134/jeq2004.0253.

Riml, J., and A. Wörman (2011), Response functions for in-stream solute transport in river networks, Water Resour. Res., 47, W06502, doi:10.1029/ 2010WR009412.

Rinaldo, A., G. Botter, E. Bertuzzo, A. Uccelli, T. Settin, and M. Marani (2006), Transport at basin scales: 1. Theoretical framework, Hydrol. Earth Syst. Sci., 10, 19 29, doi:1607-7938/hess/2006-10-19.

Samaniego, L., R. Kumar, and S. Attinger (2010), Multiscale parameter regionalization of a grid-based hydrologic model at the mesoscale, Water Resour. Res., 46, W05523, doi:10.1029/2008WR007327.

Savenije, G. (2009), HESS Opinions "The art of hydrology," Hydrol. Earth Syst. Sci., 13(2), 157161

Schoknecht, U., J. Gruycheva, H. Mathies, H. Bergmann, and M. Burkhardt (2009), Leaching of biocides used in facade coatings under laboratory test conditions, Environ. Sci. Technol., 43(24), 9321 9328, doi:10.1021/ es9019832.

Sivapalan, M. (2006), Pattern, Process and Function: Elements of a Unified Theory of Hydrology at the Catchment Scale, Encyclopedia of Hydrol. Sci., John Wiley, Chichester, UK, doi:10.1002/0470848944.hsa012.

Wittmer, I. K., and M. Burkhardt (2009), Dynamics of biocide and pesticide input, Eawag News, 67f/, 811 .

Wittmer, I. K., H. P. Bader, R. Scheidegger, H. Singer, A. Luck, I. Hanke, C. Carlsson, and C. Stamm (2010), Significance of urban and agricultural land use for biocide and pesticide dynamics in surface waters, Water Res., 44(9), 2850 2862, doi:10.1016/j.watres.2010.01.030.

Wittmer, I. K., R. Scheidegger, H. P. Bader, H. Singer, and C. Stamm (2011a), Loss rates of urban biocides can exceed those of agricultural pesticides, $\mathrm{Sci}$. Total Environ., 409(5), 920 932, doi:10.1016/j.scitotenv.2010.11.031.

Wittmer, I. K., R. Scheidegger, C. Stamm, W. Gujer, and H. Bader (2011b), Modelling biocide leaching from facades, Water Res., 45, 34533460 , doi: $10.1016 /$ j.watres.2011.04.003.

Wu, C., P. Santelmann, and J. Davidson (1974), Influence of soil temperature and moisture on terbutryn activity and persistence, Weed Sci., 22, 571574.

Zoppou, C. (2001), Review of urban storm water models, Environ. Model. Software, 16(3), 195 231, doi:10.1016/S1364-8152(00)00084-0. 